\title{
MANAJEMEN TENAGA KEPENDIDIKAN PAUD DI RA AL-IKHLAS BINAAN DHARMA WANITA KANWIL KEMENTERIAN AGAMA, PROVINSI SULAWESI SELATAN
}

\author{
Ahmad Afiif \\ Jurusan Pendidikan Islam Anak Usia Dini \\ Fakultas Tarbiyah dan Keguruan, UIN Alauddin Makassar \\ E-mail: ahmad.afif@uin-alauddin.ac.id \\ Hardianti \\ Jurusan Pendidikan Islam Anak Usia Dini \\ Fakultas Tarbiyah dan Keguruan, UIN Alauddin Makassar \\ E-mail: anthyhardianti1102@gmail.com \\ Fitri Febrianti \\ Jurusan Pendidikan Islam Anak Usia Dini \\ Fakultas Tarbiyah dan Keguruan, UIN Alauddin Makassar \\ E-mail: fitryfebb090297@gmail.com \\ Nabila \\ Jurusan Pendidikan Islam Anak Usia Dini \\ Fakultas Tarbiyah dan Keguruan, UIN Alauddin Makassar \\ E-mail: nabila12051998@gmail.com \\ Asmidar \\ Jurusan Pendidikan Islam Anak Usia Dini \\ Fakultas Tarbiyah dan Keguruan, UIN Alauddin Makassar \\ E-mail: asmidar652@gmail.com
}

\begin{abstract}
Abstrak
Penelitian ini bertujuan untuk mendeskripsikan manajemen tenaga kependidikan di RA Al-Ikhlas Binaan Dharma Wanita Kanwil Kementerian Agama, Provinsi Sulawesi Selatan penelitian ini menggunakan pendekatan kualitatif. Subjek penelitian adalah kepala sekolah dan guru RA Al-Ikhlas yang berjumlah 7 orang. Pengumpulan data dilakukan melalui angket dan wawancara. Hasil penelitian menunjukkan: 1) guru melakukan pengamatan terhadap tumbuh kembang anak secara bertahap; 2) guru melakukan konsultasi dengan kepala sekolah terhadap permasalahan yang dihadapi di dalam kelas; 3) memberikan perhatian dalam bentuk kasih sayang kepada anak didik; 4) guru mengenali kepribadian anak dengan baik; 5) guru memberi kesempatan kepada anak untuk bermain; 6) memiliki kepribadian yang ceria; 7) guru memiliki kemampuan berinteraksi dengan baik terhadap orang lain termasuk peserta didik.
\end{abstract}

Kata Kunci: Manajemen, Pendidikan Anak Usia Dini, Tenaga Kependidikan 


\begin{abstract}
This study aiimed to describe the management of education staff at RA Al-Ikhlas. This study used a qualitative approach with qualitative descriptive research. The subject of the research was headmaster and the teachers of RA Al-Ikhlas Binaan Dharma Wanita Kanwil Kementerian Agama, Provinsi Sulawesi. Data collection used observation and interviews. The result of the research showed: 1) the teacher made observation of the children development. 2) the teacher consultated with the headmaster about the problem faced in the classroom. 3) giving a good attention to the student. 4) teacher recognized the student for playing. 6) have a cheerful personality. 7) teacher had the good ability to interact with the other people, including the student. So that this research can be concluded that the management of education met the applicable standards. The education staff at RA Al-Ikhlas staff consist of principals, teachers, administrative staff, student staff, financial staff, and staff support staff such as pediatricians.
\end{abstract}

Keywords: Management, Early Childhood Education, Education Staff

\title{
PENDAHULUAN
}

Pendidikan yang diberikan kepada anak semenjak dini merupakan investasi yang berharga dalam proses tumbuhkembangnya, maka dari itu sangatlah penting memberikan suatu respon yang positif dalam merangsang pertumbuhan dan perkembangan anak baik itu dalam hal kognitif, afektif, dan psikomotornya.

Tenaga pendidik yang terlibat dalam pendidikan anak usia dini terdiri dari guru, pendamping, dan pengasuh. Tenaga pendidik ini bertugas merencanakan, melaksanakan proses pembelajaran, menilai hasil pembelajaran, serta melakukan pembimbingan, pengasuhan dan perlindungan terhadap anak didik. Tenaga pendidik PAUD ini bertugas di berbagai jenis layanan baik pada jalur pendidikan formal maupun nonformal seperti Taman Kanak-kanak (TK), Raudhatul Athfal (RA), Kelompok Bermain (KB), Taman Penitipan Anak (TPA), dan bentuk lain yang sederajat. Pendidik PAUD pada jalur pendidikan formal terdiri atas guru dan guru pendamping, sedangkan pendidik PAUD pada jalur pendidikan nonformal terdiri atas guru, guru pendamping, dan pengasuh.

Manajemen tenaga kependidikan (Mustari,2014: 213) merupakan kegiatan yang mencakup penetapan norma, standar, prosedur, pengangkatan, pembinaan, penatalaksanaan, kesejahteraan dan pemberhentian tenagan kependidikan sekolah agar dapat melaksanakan tugas dan fungsinya dalam mencapai tujuan sekolah. Manajemen tenaga pendidik dan kependidikan (Rugaiyah. 2010:99) adalah kegiatan mengelola personal pendidikan dalam melaksanakan tugas-tugas sesuai tugas dan fungsinya agar berjalan dengan efektif.

Kualifikasi dan kompetensi guru PAUD ini didasarkan pada peraturan Menteri Pendidikan Nasional Republik Indonesia Nomor 16 tahun 2007 tentang standar kualifikasi akademik dan kompetensi guru. Guru pada PAUD/ TK/RA harus memiliki kualifikasi akademikpendidikan minimum diploma empat (D IV) atau sarjana (S1)

2 NANAEKE - Indonesian Journal of Early Childhood Education, Vol. 2, No. 1, Juni 2019 
dalam bidang pendidikan anak usia dini atau psikologi yang diperoleh dari program studi yang terakreditasi. Sementara itu bagi guru PAUD yang belum memenuhi kualifikasi akademik dan kompetensi disebut guru pendamping dan pengasuh. Menurut peraturan Menteri Pendidikan Nasional No. 58 tahun 2009 tentang standar pendidikan anak usia dini kualifikasi akademik dan kompetensi pendamping yaitu memiliki ijazah D-II PGTK dari Perguruan Tinggi dan memiliki ijazah minimal Sekolah Menengah Atas (SMA) atau sederajat dan memiliki sertifikat pelatihan/ pendidikan/ kursus PAUD yaitu minimal Sekolah Menengah Atas (SMA) dan sederajat.

Kompetensi guru PAUD dan pendamping seperti yang dijelaskan dalam permendiknas No. 26 tahun 2007 dan permendiknas No. 58 tahun 2009 meliputi kompetensi pedagogik, kompetensi kepribadian, kompetensi sosial, dan kompetensi profesional. Sementara itu masih dalam permendiknas No. 58 tahun 2009 dijelaskan pula mengenai kompetensi untuk mengasuh PAUD yaitu memahami dasar-dasar pengasuhan, terampil melaksanakan pengasuhan, bersikap dan berperilaku sesuai dengan kebutuhan psikologi anak.

Selain itu, ada beberapa faktor yang mempengaruhi kinerja guru, diantaranya yaitu pertama, faktor kemampuan, secara umum kemamuan ini terbagi menjadi dua yaitu kemampuan potensi (IQ) dan kemampuan reality (knowledge dan skil), kedua faktor motivasi, motivasi terbentuk dari sikap karyawan dalam menghadapi kualitas kerja.

Kinerja pengasuh PAUD sangatlah dipengaruhi oleh beberapa faktor. Mulai dari faktor yang mempengaruhi kinerja individu itu sendiri sampai dengan faktor yang mempengaruhi kinerja kelompok dan akhirnya mempengaruhi kinerja orgaisasi dalam hal ini sekolah. Maka dari itu, penilaian kinerja pengasuh ini sangatlah penting untuk diperhatikan, penilaian ini dilakukan untuk mengetahui kualitas kerja pengasuh PAUD.

Berdasarkan hasil penelitian ini untuk mengetahui manajamen tenaga kependidikan PAUD dimana manajemen yang menitikberatkan perhatiannya kepada soal-soal pegawai didalam suatu organisasi, adapun untuk mengetahui Manajemen Tenaga pendidik di mulai dari perencanaan dan seleksi tenaga pendidik baru di PAUD dan dapat disimpulkan bahwa: dalam rekrutmen tenaga pendidik melalui beberapa tahapan yaitu 1), perencanaan Tenaga pendidik, 2).seleksi calon tenaga pendidik yang memenuhi syarat.untuk mengasuh PAUD yaitu memahami dasardasar pengasuhan, terampil melaksanakan pengasuhan, bersikap dan berperilaku sesuai dengan kebutuhan psikologi anak.

Manajemen pendidik dan tenaga kependidikan Indonesia memang mulai menampakkan kecenderungan baik dibandingkan tahun-tahun sebelumnya. Sertifikasi dan pemberian tunjangan sebagai alat untuk mendongkrak kesejahteraan pendidik mulai berjalan, walaupun disana sini masih ada kekurangan. Salah satu kekurangan yaitu masih banyak pendidik dan tenaga pendidik swasta, dan pendidik dan tenaga pendidik daerah terpencil kurang tersentuh kebijakan yang 
mensejahterakan.

Kebijakan yang dikeluarkan oleh pemerintah juga menunjukkan perhatian terhadap pendidik dan tenaga kependidikan semakin baik. Beberapa contoh dari hal tersebut yaitu Undang-Undang Republik Indonesia Nomor 14 Tahun 2005 tentang Guru dan Dosen seperti yang dikatakan oleh Menteri Pendidikan Nasional Dr. Bambang Sudibyo setelah pengesahan Undang-Undang Guru dan Dosen tersebut bahwa guru yang belum memenuhi kualifikasi dan kompetensi yang ditetapkan akan diberikan kesempatan untuk memenuhi selama 10 tahun, Peraturan Pemerintah Republik Indonesia Nomor 41 Tahun 2009 tentang tunjangan profesi Guru dan Dosen, Tunjangan Khusus Guru dan Dosen, serta Tunjangan Kehormatan Profesor, Peraturan Menteri Pendidikan Nasional Nomor 24 Tahun 2008 mengenai Tenaga Administrasi Sekolah, Peraturan Menteri Pendidikan Nasional 2008 Nomor 28 Tahun 2010 tentang Penugasan Guru sebagai Kepala Sekolah, penilaian kinerja Guru, dan lainnya.

Pemerintah Indonesia melakukan berbagai upaya untuk meningkatkan jumlah dan mutu Guru dan Tenaga kependidikan PAUD dan Pendidikan Masyarakat dengan program prioritas pada penguatan peran guru dan tenaga kependidian PAUD dan Pendidikan Masyarakat sebagai pelaku yang kuat, guru dan tenaga kependidikan PAUD dan Pendidikan Masyarakat yang mulia, profesional, dan sejahtera untuk mewujudkan pembelajaran yang bermutu, peningkatan kualitas pengelolaan guru dan tenaga kependidikan PAUD dan Pendidikan Masyarakat yang meluas, merata dan berkeadilan. Sasaran kinerja tahun 2017 meliputi sertifikasi profesi pendidik, kompetensi guru dan tenaga kependidikan PAUD dan Pendidikan Masyarakat, profesi pembinaan karir, kesejahteraan dan harlindung dan peningkatan kualifikasi (Abdoellah, 2017).

Raudhatul Athfal Al-Ikhlas merupakan salah satu Pendidikan Anak Usia Dini yang berada di wilayah makassar sulawesi selatan. Sekolah ini berdiri sejak tahun 1989 dengan jumlah anak didik yang terus bertambah dari tahun ke tahun. Di tahun 2018 ini jumlah anak didik sebanyak 117 anak. Sekolah ini sudah sangat lama berdiri dan dengan berdirinya sekolah ini banyak masyarakat yang memasukkam anaknya di Raudhatul athfal A Al-Ikhlas. Manajemen yang ada disesuaikan dengan prosedur pendidikan yang seharusnya, khususnya pada tingkat RA, termasuk manajemen tenaga kependidikan PAUD. Oleh karena itu, penelitian ini bertujuan untuk mengetahui gambaran penerapan manajemen tenaga kependidikan di Raudhatul athfal A Al-Ikhlas binaan Dharma Wanita Kanwil Kementerian Agama Provinsi Sulawesi Selatan. Hasil penelitian ini diharapkan dapat menjadi rujukan bagi PAUD lainnya khususnya dalam hal manajemen tenaga kependidikan PAUD.

\section{METODE PENELITIAN}

Jenis penelitian yang digunakan adalah penelitian deskriptif kualitatif. Penelitian deskriptif kualitatif yaitu rangkaian kegiatan untuk memperoleh data yang

4 NANAEKE - Indonesian Journal of Early Childhood Education, Vol. 2, No. 1, Juni 2019 
bersifat apa adanya tanpa ada dalam kondisi tertentu yang hasilnya lebih menekankan pada makna. Subjek dalam penelitian ini yang menjadi sumber informan utama berjumlah dua orang yaitu kepala sekolah dan guru di RA Al-Ikhlas binaan Dharma Wanita Kanwil Kementerian Agama, provinsi Sulawesi Selatan. Adapun pemilihan subjek berdasarkan kriteria sekolah: (1) minimal telah menamatkan anak didik selama 3 tahun; (2) dapat izin operasional dari dinas pendidikan; (3) mudah di akses oleh peneliti; (4) kepala sekolah dan guru bersedia menjadi subjek penelitian. Data yang dikumpulkan menggunakan metode wawancara dan angket.

\section{HASIL DAN PEMBAHASAN}

Hasil penelitian yang dilakukan di RA Al-Ikhlas binaan Dharma Wanita Kanwil Kementerian Agama, provinsi Sulawesi Selatan diperoleh jumlah guru dengan kualifikasi sarjana jurusan PAUD sebanyak 3 orang dan 3 orang guru jurusan non PAUD. Umur guru rata rata 40 tahun dan telah mengikuti beberapa pelatihan yang berkaitan degan PAUD.

Dari hasil wawancara dengan para tenaga pendidik di RA Al-lkhlas dapat disimpulkan bahwa ada beberapa pelatihan/workshop yang pernah diikuti diantaranya pelatihan kurikulum 2013, pelatihan tumbuh kembang anak, pelatihan pembuatan RPP, dan lain-lain. Pelatihan ini dilakukan secara bergantian oleh para guru, setiap pelatihan hanya diikuti oleh beberapa guru saja.

Adapun hasil angket yang terdiri atas 7 pertanyaan diperoleh rata rata guru telah melaksanakan tugas utama sebagai guru PAUD. Angket tersebut meliputi pengamatan terhadap tumbuh kembang anak, konsultasi kepada kepala sekolah berkaitan dengan permasalahan yang dihadapi di kelas, perhatian guru terhadap anak, mengenal kepribadian anak, memberi kesempatan kepada anak untuk bermain, berkepribadian, dan kemampuan berinteraksi dengan baik.

Guru rutin membuat laporan hasil belajar tentang proses tumbuh kembang anak didik. Jika guru mendapat sebuah masalah di sekolah, maka guru akan berkonsultasi dengan kepala sekolah atau guru lainnya. Kegiatan ini bertujuan untuk memecahkan masalah yang dihadapi dan juga akan terjalin hubungan yang baik antara kepala sekolah dengan guru, guru dengan guru, dan staf lainnya.

Setiap guru melakukan pengamatan tumbuh kembang pada anak didik baik pada proses pembelajaran sedang berlangsung ataupun pada saat anak didik sedang bermain (mulai datang sampai pulang sekolah). Adapun aspek yang dinilai ada 6 yaitu aspek fisik motorik, kognitif, bahasa, moral agama, sosial emosional dan seni. Apabila guru mengalami kesulitan dalam mengajar, kesulitan dalam melakukan pengamatan tumbuh kembang dan kesulitan lainnya maka guru akan berkonsultasi dengan kepala sekolah atau staf lainnya untuk bisa mendapatkan solusi atau jalan keluar dari permasalahan yang dihadapi.

Tenaga pendidik mudah bergaul dan beradaptasi dengan lingkungannya, 
khususnya di sekolah. Kondisi ini membuat anak didik nyaman dan aman saat berada di sekolah. Tenaga pendidik mengerti pribadi setiap anak didiknya karena setiap anak memiliki karakter yang berbeda sehingga perlu memberikan perlakuan yang berbeda pula. Guru yang gampang bergaul atau bersosialisasi akan lebih percaya diri, nyaman, dan kehidupannya lebih sehat serta bahagia karena memiliki banyak teman dan jaringan yang luas dibandingkan mereka yang jarang bergaul.

Kepala sekolah di RA Al-lkhlas menjalin kerjasama/hubungan yang baik dengan para guru dan staf tenaga kependidikan lainnya sehingga para staf merasa nyaman berada di sekolah. Selain itu kepala sekolah selalu memberikan kesempatan kepada para guru untuk mengikuti pelatihan PAUD secara bergantian. Pelatihan tersebut diikuti secara bergantian oleh para guru, dimana dalam tiap pelatihan diikuti oleh 2-3 guru. Pelatihan terakhir yang diikuti oleh guru adalah pelatihan kurikulum 2013. Pelatihan bertujuan untuk mengembangkan skill dan kemampuan guru serta menambah wawasan guru dalam hal ketenaga pendidikan demi terciptanya suasana kelas yang nyaman, ceria dan menyenangkan.

Guru melakukan pengamatan terhadap tumbuh kembang anak secara bertahap, dimana segala aktivitas yang dilakukan oleh anak mulai dari datang sampai pulang sekolah harus diamati oleh guru. Tujuan dari melakukan pengamatan tumbuh kembang anak adalah untuk mengetahui tingkat perkembangan yang dialami oleh anak. Hasil pengamatan tersebut kemudian dijadikan bahan untuk melakukan penilaian. Ada 6 aspek perkembangan yang harus diamati oleh guru yaitu aspek fisik motorik, kognitif, moral agama, sosial emosional, bahasa dan seni. Pengamatan tumbuh kembang anak harus ditingkatkan agar pemberian stimulus dapat dapat dilakukan secara maksimal.

Guru melakukan konsultasi terhadap permasalahan yang dihadapi di dalam kelas kepada kepala sekolah. Konsultasi adalah kegiatan yang memberikan alternatif bantuan dalam memecahkan suatu prmasalahan, khususnya permasalahan yang berkaitan dengan tugas-tugas profesionalisme kelembagaan PAUD. Konsultasi bertujuan untuk bisa menemukan jalan keluar dari suatu permasalahan yang dihadapi, seperti permasalahan dalam melakukan penilaian tumbuh kembang anak. Nah dengan melakukan konsultasi dengan kepala sekolah maka guru akan diberikan solusi dari permasalahan tersebut serta dapat menambah wawasan guru.

Memberikan perhatian dalam bentuk kasih sayang kepada anak didik. Anak adalah sumber daya manusia sebagai pewaris bangsa dan negaranya. Perhatian adalah perilaku yang diberikan oleh guru kepada anak disamping perhatian yang diberikan oleh orang tua kepada anaknya. Dengan memberikan perhatian kepada anak, maka anak akan merasa bersemangat untuk bereksplorasi sehingga pengetahuan anak akan bertambah. Selain itu, dengan memberikan perhatian, anak menganggap bahwa dirinya dihargai oleh guru. Masa anak-anak adalah masa yang sangat aktif sehingga membutuhkan penawasan dan perhatian lebih dari guru.

6 NANAEKE - Indonesian Journal of Early Childhood Education, Vol. 2, No. 1, Juni 2019 
Salah satu upaya mencapai keberhasilan dalam proses pembelajaran adalah mengetahui kepribadian dan karakter anak. Setiap anak memiliki karakter dan kepribadian yang beda sehingga perlu memberikan perlakuan yang beda. Kepribadian anak terbentuk dari 3 lingkup yaitu lingkup keluarga, lingkup sekolah dan lingkup masyarakat. Lingkungan di sekolah tentunya tidak lepas dari peranan guru, dimana guru berperan aktif untuk membentuk kepribadian anak agar anak menjadi pribadi yang baik. Seorang guru hendaknya dapat mengenali kepribadian siswa yang nantinya dapat membantu guru untuk melihat karakter anak tersebut. Dengan memahami dan mengetahui kepribadian anak maka proses belajar mengajar dapat lebih dioptimalkan.

Guru memberikan kesempatan kepada anak untuk bermain. Dunia anak adalah dunia bermain, dimana mereka belajar sambil bermain, bermain sambil belajar. Anak berhak untuk bereksplorasi dalam mengetahui dunia diluar dari lingkungan keluarganya. Dengan memberikan kesempatan kepada anak untuk bermain akan mampu membentuk aspek perkembangan anak yang berupa aspek kognitif dan aspek perkembangan lainnya. Anak belajar dalam bentuk bermain, bukan memaksa anak agar bisa membaca dan menulis seperti anak SD. Dengan memaksakan kehendak anak, membuat anak merasa tertekan sehingga daya kreativitas anak akan terhambat.

Guru harus memiliki keperibadian ceria agar peserta didik mau berinteraksi dan terbuka sehingga anak bersedia menceritakan peristiwa ataupun permsalahan yang dialami anak. Kepribadian ceria adalah salah satu kepribadian yang harus dimiliki oleh seorang guru dalam mengajar khususnya guru PAUD. Selain itu keperibadian ceria dimiliki guru agar dapat meningkatkan mood anak saat proses pembelajaran. Selain itu keperibadian ceria juga dapat membuat anak aman dan nyaman sehingga anak mudah menangkap pembelajaran. Kepribadian yang ceria disenangi oleh banyak orang apalagi anak-anak karena anak-anak senang dengan guru yang ramah dan murah senyum.

Guru memiliki kemampuan berinteraksi dengan baik terhadap orang lain termasuk peserta didik (standar kompetensi sosial guru). Menurut Walgito (2003: 57 ) interaksi sosial adalah hubungan antara individu satu dengan individu yang lain. Guru yang profesional adalah guru yang mampu berinteraksi dengan orang lain, dan menjalin hubungan yang baik terhadap sesama terutama kepada peserta didik. Interaksi belajar mengajar adalah kegiatan timbal balik antara guru dengan anak didik, atau dengan kata lain bahwa interaksi belajar mengajar adalah suatu kegiatan sosial, karena antara anak didik dengan temannya, antara si anak didik dengan gurunya ada suatu komunikasi sosial atau pergaulan. Interaksi yang baik sangat dibutuhkan oleh seorang guru untuk bisa berkomunikasi dengan peserta didik secara baik. 


\section{SIMPULAN}

Dari hasil penelitian dapat dengan para tenaga pendidik di RA Al-Ikhlas dapat disimpulkan bahwa 1) ada beberapa pelatihan/workshop yang pernah diikuti diantaranya pelatihan kurikulum 2013, pelatihan tumbuh kembang anak, pelatihan pembuatan RPP, dan lain-lain. Pelatihan ini dilakukan secara bergantian oleh para guru, setiap pelatihan hanya diikuti oleh beberapa guru saja.2) Guru rutin membuat laporan hasil belajar tentang proses tumbuh kembang anak didik. Jika guru mendapat sebuah masalah di sekolah, maka guru akan berkonsultasi dengan kepala sekolah atau guru lainnya. Kegiatan ini bertujuan untuk memecahkan masalah yang dihadapi dan juga akan terjalin hubungan yang baik antara kepala sekolah dengan guru, guru dengan guru, dan staf lainnya. 3) Setiap guru melakukan pengamatan tumbuh kembang pada anak didik baik pada proses pembelajaran sedang berlangsung ataupun pada saat anak didik sedang bermain (mulai datang sampai pulang sekolah). Adapun aspek yang dinilai ada 6 yaitu aspek fisik motorik, kognitif, bahasa, moral agama, sosial emosional dan seni. Apabila guru mengalami kesulitan dalam mengajar, kesulitan dalam melakukan pengamatan tumbuh kembang dan kesulitan lainnya maka guru akan berkonsultasi dengan kepala sekolah atau staf lainnya untuk bisa mendapatkan solusi atau jalan keluar dari permasalahan yang dihadapi. 4) Tenaga pendidik di RA Al-Ikhlas mudah bergaul dan beradaptasi dengan lingkungannya, khususnya di sekolah, sehingga anak didik nyaman dan aman saat berada di sekolah. Tenaga pendidik mengerti pribadi setiap anak didiknya karena setiap anak memiliki karakter yang berbeda sehingga perlu memberikan perlakuan yang berbeda pula. 5) Kepala sekolah di RA Al-Ikhlas menjalin kerjasama/hubungan yang baik dengan para guru dan staf tenaga kependidikan lainnya sehingga para staf merasa nyaman berada di sekolah. Selain itu kepala sekolah selalu memberikan kesempatan kepada para guru untuk mengikuti pelatihan PAUD secara bergantian.

\section{DAFTAR PUSTAKA}

Abdoellah. (2017). Mewujudkan Guru dan Tenaga Kependidikan Paud dan Dikmas Yang Mulia, Profesional, dan Sejahtera Untuk Membentuk Insan Indonesia Yang Bekarakter. Jurnal IImiah PGTK PAUD dan Dikmas Vol.12, No.1. https://www.google.com/url?sa=t\&source=web\&rct=j\&url=http://journal.unj. ac.id/unj/index.php/jiv/article/view/2798\&ved=2ahUKEwiiyomgxMnfAhVBgl 8KHaEnCNoQFjAAegQIBRAB\&usg=AOvVaw3x_DuZaBUyeUbwOGYE7dVK

Rusmiati, Rusi Aliyyah. (2017). Pengelolaan Pendidik dan Tenaga Kependidikan. Jakarta Selatan: Polimedia Publishing. https://www.google.com/url?sa=t\&source=web\&rct=j\&url=https://www.resea rchgate.net/publication/326775111_Pengelolaan_Pendidik_dan_Tenaga_Ke pendidikan\&ved=2ahUKEwiErLLCxMnfAhVCrY8KHVAxCDcQFjAAegQIBBAB\&us

8 NANAEKE - Indonesian Journal of Early Childhood Education, Vol. 2, No. 1, Juni 2019 


$$
\text { g=AOvVaw2686ybCDIgoahxJbsnIFhO }
$$

Suyadi. (2017). Manajemen PAUD TPA-KB-TK/RA Mendirikan, Mengelola, dan Mengembangkan PAUD. Yogyakarta: Pustakapelajar

Triwianto, T. Manajemen Pendidik, Tenaga Kependidikan dan Upaya Memperkuat Karakter Bangsa (Tanpa tahun). https://www.google.com/url?sa=t\&source=web\&rct=j\&url=http://ap.fip.um.a c.id/wp-content/uploads/2015/04/Teguh-Triwiyanto-UM-ManajemenPendidik-Tenaga-Kependidikan-dan-Upaya-Memperkuat-KarakterBangsa.pdf\&ved=2ahUKEwjH4t_wwsnfAhXMro8KHf5A2wQFjABegQICBAB\&usg=AOvVaw12R-OmgeujJbyetUE2p_2l

Usa Muslih. (2005). Guru dalam Undang-Undang No. 14/2005. JPI FIAI Jurusan Tarbiyah Volume XIII Tahun VIII Desember 2005: hl.13-14. https://www.google.com/url?sa=t\&source=web\&rct=j\&url=https://media.neli ti.com/media/publications/69398-ID-guru-dalam-uuno142005. pdf\&ved=2ahUKEwilp6LMw8nfAhWDvo8KHfvMA5kQFjAAegQIAxAB \&usg=AOvVawOK8mLNUPcEFS2IdtgGb4s_ 